\title{
A Novel Route for the Preparation of Gold Nanoparticles in Polycaprolactone Nanofibers
}

\author{
Simón Yobanny Reyes-López, ${ }^{1}$ Delfino Cornejo-Monroy, ${ }^{2}$ and Gerardo González-García ${ }^{3}$ \\ ${ }^{1}$ Instituto de Ciencias Biomédicas, Universidad Autónoma de Ciudad Juárez, Envolvente del PRONAF y Estocolmo s/n, Cuidad Juárez, \\ 32300 México, CHIH, Mexico \\ ${ }^{2}$ Instituto de Ingeniería y Tecnología, Universidad Autónoma de Ciudad Juárez, Avenida del Charro 450 Norte, \\ Colonia Partido Romero, Cuidad Juárez, 32310 México, CHIH, Mexico \\ ${ }^{3}$ Departamento de Física Aplicada, CINVESTAV-Unidad Mérida, Km 6 Antigua Carretera a Progreso, 97310 Mérida, YUC, Mexico
}

Correspondence should be addressed to Simón Yobanny Reyes-López; simon.reyes@uacj.mx

Received 17 October 2014; Revised 22 January 2015; Accepted 9 March 2015

Academic Editor: Jian Fang

Copyright (C) 2015 Simón Yobanny Reyes-López et al. This is an open access article distributed under the Creative Commons Attribution License, which permits unrestricted use, distribution, and reproduction in any medium, provided the original work is properly cited.

\begin{abstract}
A facile strategy for the fabrication of polycaprolactone (PCL) nanofibers containing gold nanoparticles (AuNPs) is proposed. The method is based on electrospinning nanosuspensions loaded with passivated Au nanoparticles. The optical property of gold nanoparticles synthesized was observed by UV-visible absorption spectra. Morphology and structure of the Au-PCL hybrid nanofibers were characterized by scanning electron microscopy, scanning transmission electron microscopy, and Fourier transformed infrared spectroscopy. The results of investigations by UV-visible and dynamic light scattering confirmed the presence of gold nanoparticles with diameters less than $10 \mathrm{~nm}$. The STEM images show the presence of gold nanoparticles and gold agglomerates with diameter around 30 to $180 \mathrm{~nm}$ distributed over the surface of nanofibers, which is likely due to the increased incidence of agglomerations of AuNPs, due to drying process used.
\end{abstract}

\section{Introduction}

Electrospinning has been recognized as an efficient and relatively simple technique for the preparation of polymer nanofibers, which can be obtained from micrometric or nanometric scale [1]. This technique involves applying a high electric field to charged droplets of a polymeric fluid, which may be molten, or a solution coming out from the needle, which acts as one of the electrodes. The electrospinning process results in ultrafine continuous fibers in the order of few nanometers with large surface areas, characteristics needed for its potential applications. Electrospinning is applied to a wide range of polymers. Mat thickness can be controlled by adjusting the solution properties and processing parameters $[1,2]$. It has been reported recently that electrospinning is a technique that allows for composites with metal particles, ceramics or polymers [1-3]. The resultant composites maintain the properties of polymer, ceramic and metal nanoparticles, and also are expected to have potential applications in many fields, such as biomaterials, chemistry, and physics [1-4].

Recently electrospinning technology has been used for fabricating gold nanoparticle-polymer composites and other several kinds of materials have been reported with electronic, magnetic, and optical properties and their applications to catalysis and biology [4]. Mainly, aliphatic polyesters possess these desirable properties, and among the numerous polyesters studied so far, polycaprolactone (PCL) has proven to be the most attractive and useful class of biodegradable polyesters because of their proven biocompatibility and good material properties $[5,6]$. PCL is an aliphatic polyester that can be enzymatically degraded in earth environments, while it is degraded through nonenzymatic hydrolysis in the body. At present, PCL has been considered for several biomedical applications, such as sustained drug delivery systems, tissue engineered skin regeneration, scaffolds for supporting 


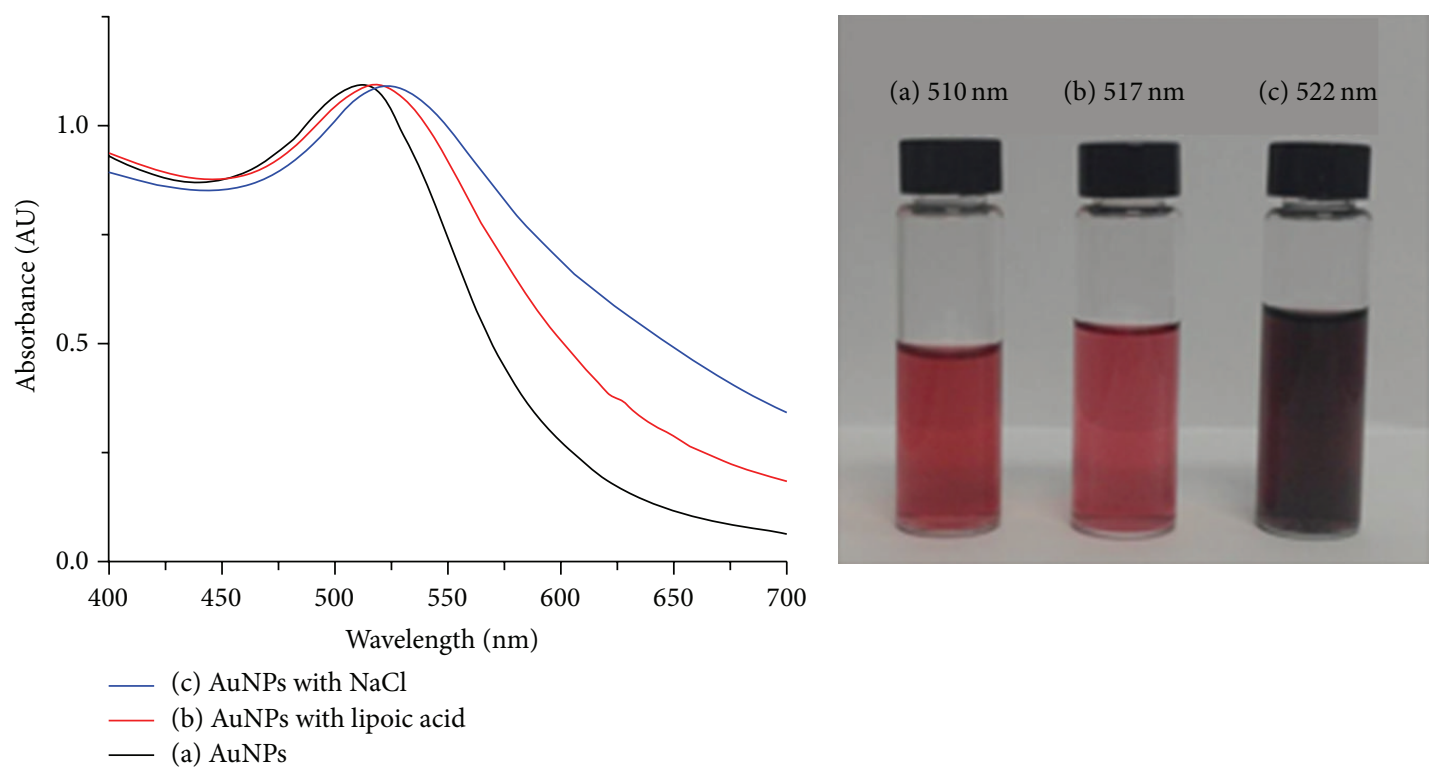

FIgURE 1: UV-Vis spectra of aqueous solutions containing (a) AuNPs, (b) AuNPs with lipoic acid, and (c) AuNPs with NaCl. The inset shows images of AuNPs at the same conditions.

fibroblasts and osteoblasts growth, and nanocomposites for bone repair, in the ureteral substitution and newly in electrospun composite nanofibers [7-9].

The PVA, PEO, and PVP electrospun nanofibers containing AuNPs such as AuNPs/PVA, AuNPs/PEO, and AuNPs/PVP have been reported [10-13]. The studies on the incorporation of AuNPs into electrospun nanofibers have been conducted by adding chloroauric acid $\left(\mathrm{HAuCl}_{4} \cdot 4 \mathrm{H}_{2} \mathrm{O}\right)$ into electrospun solution. Generally, there are two methods to reduce $\mathrm{Au}^{+}$to AuNPs in electrospinning field. The first one consists in treating a polymer solution containing $\mathrm{Au}^{+}$ with reduction agents, for instance, sodium citrate, sodium borohydride, or ascorbic acid, while the second consists in chemical reduction with polymers like PVP or DMF before electrospinning process [10-14]. Recently, PCL nanofiber films were hydrophilically modified and incubated in the AuNP solutions in order to assemble Electrospun Polymer Nanofiber film with excellent SERS activity [15].

In this paper, we described a novel and easy method for the electrospinning of PCL nanofibers containing AuNPs. The AuNPs were easily formed in aqueous solution before electrospinning. Therefore, it is expected to have potential for the application on biomaterials, such as tissue engineering scaffold or for practical applications, such as heterogeneous catalysis and SERS. It is often necessary to support these nanoparticles on solid substrates processed in nonaqueous media.

\section{Materials and Methods}

All the chemicals used were of analytical grade. High purity water was employed. Chloroauric acid $\left(\mathrm{HAuCl}_{4} \cdot 4 \mathrm{H}_{2} \mathrm{O}\right)$, sodium borohydride $\left(\mathrm{NaBH}_{4}\right)$, poly $\varepsilon$-caprolactone with an average molecule weight $(\mathrm{Mw})$ of 80,000 , lipoic acid $(\geq 98)$, and acetone $(\geq 99.5 \%)$ were purchased from Aldrich. The polymer solution with concentration of $10 \mathrm{wt} \%$ was prepared by dissolving PCL in acetone and stirred at room temperature. The method for the preparation of gold nanoparticles is the simple aqueous reduction of chloroauric acid by sodium borohydride [4,10-14]. The particle size was controlled by the initial concentrations of reactants and lipoic acid is also used to functionalize and prevent the growth of nanoparticles.

For preparing AuNPs, $22.5 \mathrm{mg} \mathrm{HAuCl} \cdot 4 \mathrm{H}_{2} \mathrm{O}$ was diluted to $130 \mathrm{~mL}$ with water, and then $12.08 \mathrm{~mL}$ of aqueous $0.5 \%$ $\mathrm{NaBH}_{4}$ was dropped into this solution, under vigorous stirring. The solution turned a red color, showing the formation of AuNPs. The gold nanoparticles were separated in a rotavapor (BUCHI Rotavapor R215) after the addition of lipoic acid.

The preparation of nanofibers by electrospinning was carried out by adding a weight percent (1\%) of gold nanoparticles to a viscous solution of PCL. The resulting viscous solution of $\mathrm{PCL} /$ gold nanoparticles was loaded into a syringe connected to a stainless steel needle of $1.25 \mathrm{~mm}$ inner diameter. The steel needle was connected to a high-voltage generator, and an aluminum foil served as the counter electrode. A dense web of fibers was collected on the aluminum foil. The utilized electrical potential amounted to $13 \mathrm{kV}$, the distance between the capillary and the substrate electrode was $13 \mathrm{~cm}$, and the feed rate of the solution was $1 \mathrm{~mL} / \mathrm{h}$ through a syringe pump. The electrospinning was performed at $22^{\circ} \mathrm{C}$.

The morphologies of the PCL-Au nanocomposites collected on carbon-coated copper grids were observed with a JEOL JSM-6400 (SEM) operated at $20 \mathrm{kV}$. Before the observation, the scaffolds were coated with platinum using a sputter coating. The diameter of the fibers was measured from the SEM photographs. FTIR spectra were taken with an Alpha Platinum-ATR spectrometer and transmission spectra of the samples were obtained by forming fiber films. UV-Vis absorption spectra were measured at room temperature in a 

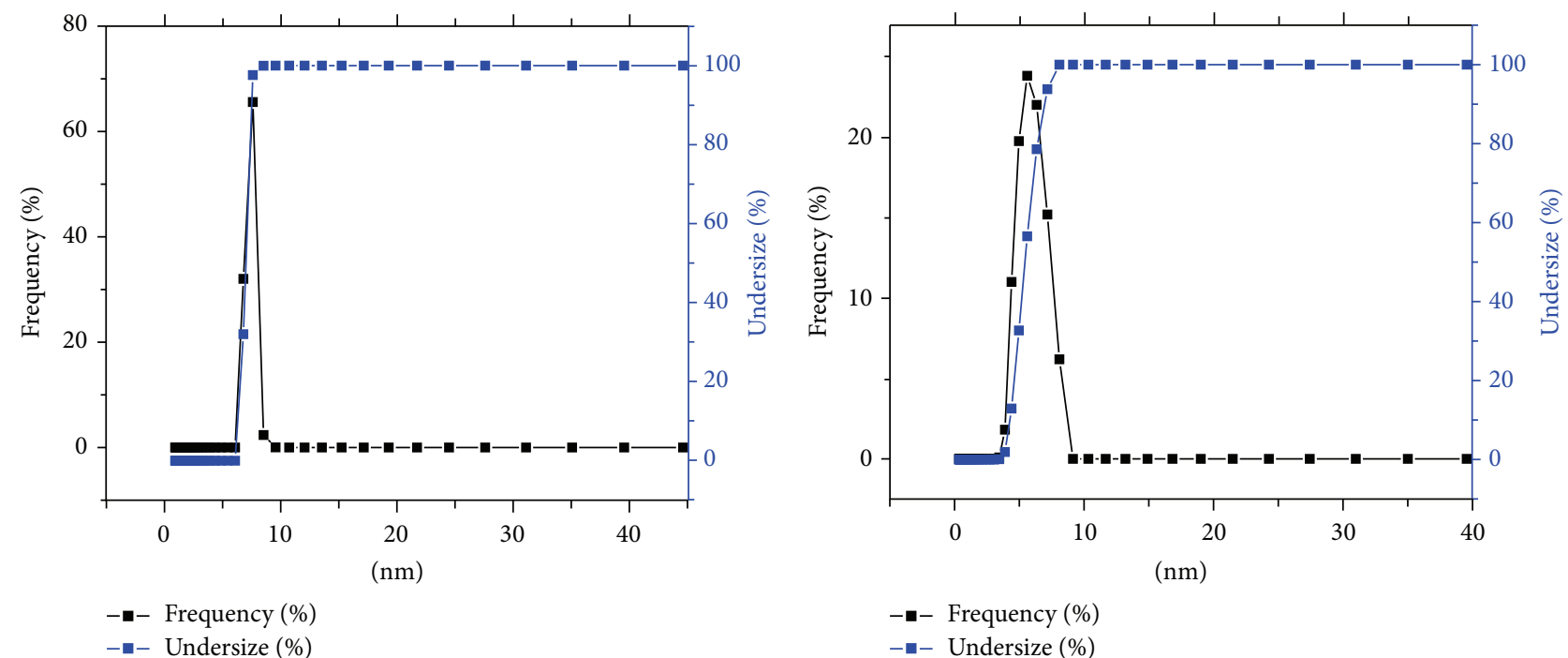

(a)

(b)

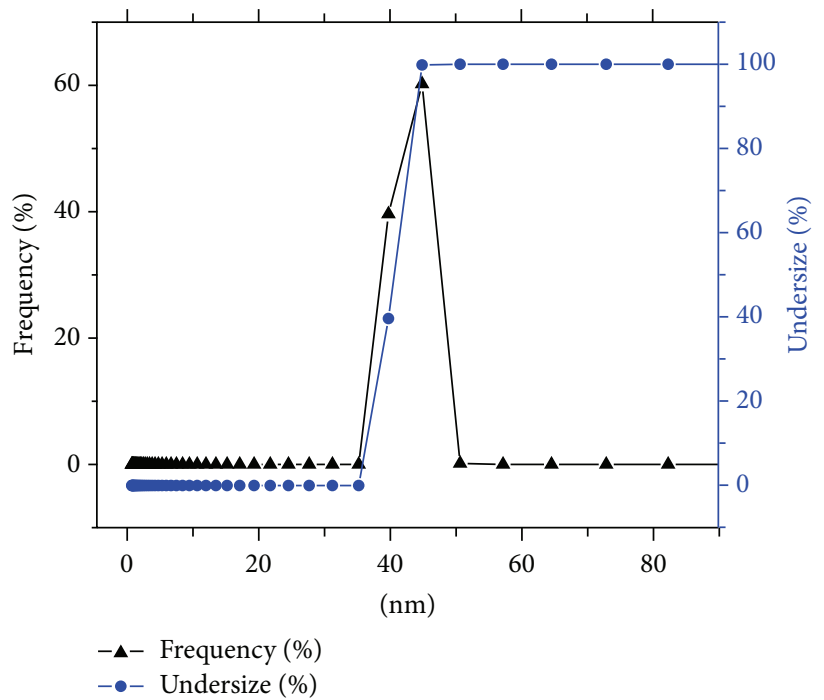

(c)

Figure 2: Particle size distributions curves for: (a) AuNPs, (b) AuNPs with lipoid acid, and (c) AuNPs with NaCl.

Cary 100 spectrophotometer (Varian Corp.) with a variable wavelength between 100 and $900 \mathrm{~nm}$ using a $10 \mathrm{~mm}$ quartz cell. The particle size and distribution were measured in an HORIBA SZ-100 Nanoparticle Analyzer with dynamic light scattering technology.

\section{Results and Discussions}

Gold nanoparticles in the range of 5-6 nm were synthesized by the reduction of gold (III) chloride trihydrate $(0.5 \mathrm{mM})$ by sodium borohydride $(1.25 \mathrm{mM})$. The solution exhibited a red wine color (inset (a), Figure 1) with initial absorption at $510 \mathrm{~nm}$ (Figure 1). This feature is commonly known as the surface plasmon resonance peak and depends on particle size. In inset (c), Figure 1, the change of color is observed to a purple tone of the synthesized nanoparticles due to the addition of $\mathrm{NaCl}$. The salt causes the agglomeration of the particles, forming larger colloids in the solution, producing a change in the absorption spectrum in the visible to $522 \mathrm{~nm}$. As reported in literature, red color and peaks of wavelength around $510-522 \mathrm{~nm}$ are characteristic for gold nanoparticles in the range of 2.5 to $6.0 \mathrm{~nm}$, and purple color with absorption around $522-536 \mathrm{~nm}$ is attributed to 30 to $60 \mathrm{~nm}[14,16]$. Inset (c), Figure 1, shows the nanoparticles functionalized with lipoic acid are tested with $\mathrm{NaCl}$. It was observed that the nanoparticle solution retains the original red color due to a protective effect of lipoic acid functionalization, which prevents that the dissociated salt affects the polarity in the particles to produce agglomerates.

Since excess amounts of reducing agent were used, the reactions were assumed to be complete. This assertion was consistent with UV-Vis spectroscopy in the wavelength range of $200-300 \mathrm{~nm}$, where no residues of $\mathrm{H}_{4} \mathrm{AuCl}_{4}$ could be detected. The average particle size distributions in Figure 2 


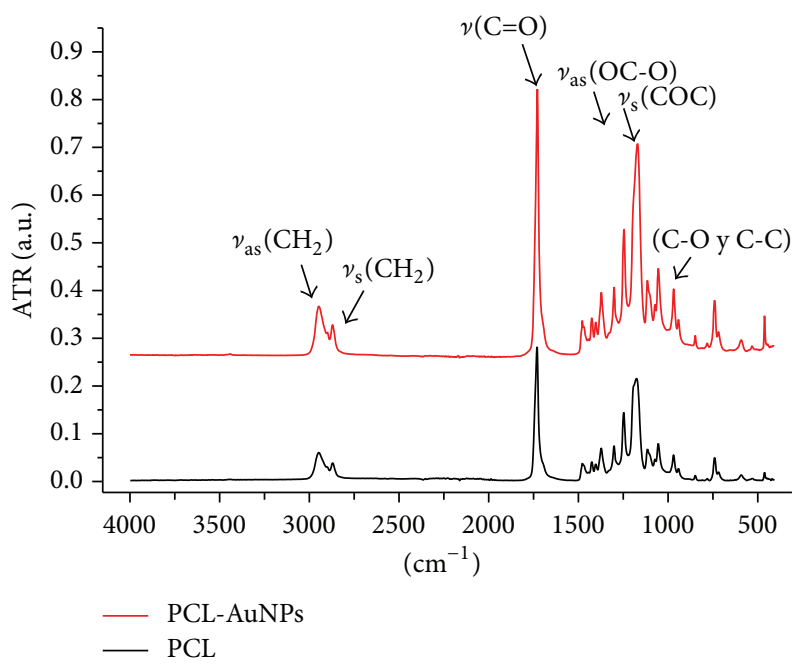

Figure 3: Infrared spectrum of electrospun PCL and PCL-AuNPs fibers in the $4000-400 \mathrm{~cm}^{-1}$ region.

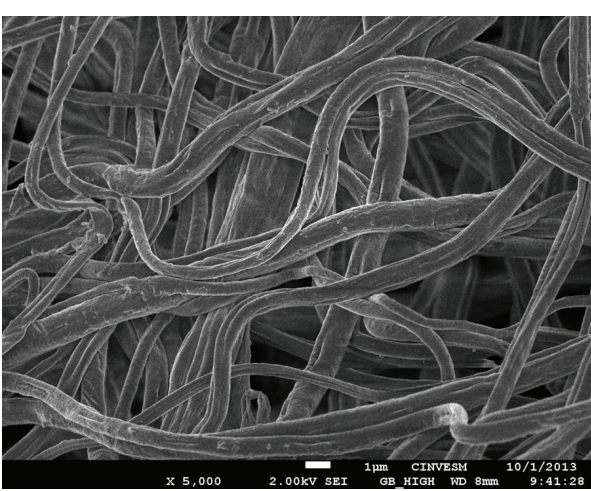

(a)

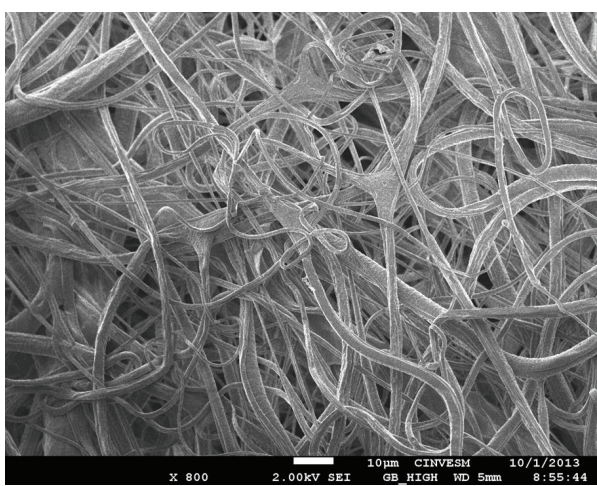

(c)

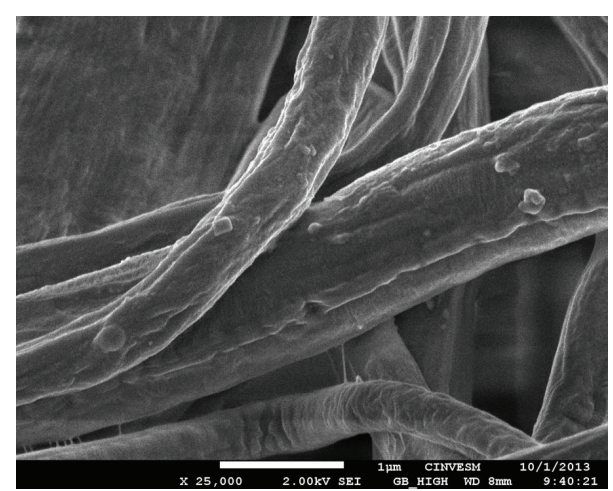

(b)

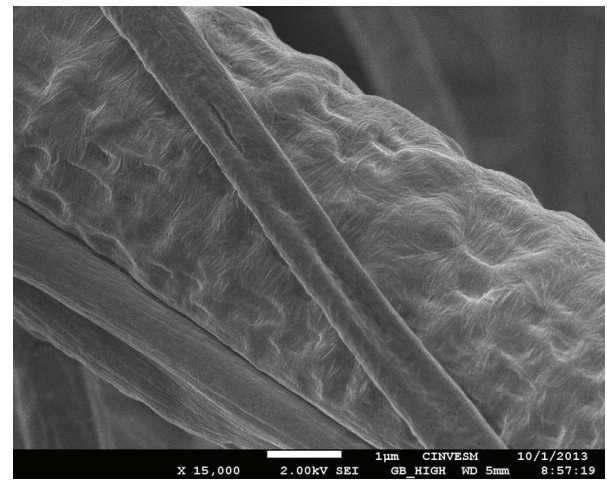

(d)

FIGURE 4: SEM images of fibers: (a) electrospun PCL 5,000x; (b) electrospun PCL 25,000x; (c) electrospun PCL-AuNPs 800x; and (d) electrospun PCL-AuNPs 15,000x.

of AuNPs, AuNPs with lipoid acid, and AuNPs with $\mathrm{NaCl}$ synthesized are $5.5 \mathrm{~nm}$; the standard deviation is in the range of $\pm 1 \mathrm{~nm}, 5.8 \pm 0.4 \mathrm{~nm}, 40.2 \pm 2.4 \mathrm{~nm}$, respectively. It is remarkable that the functionalization with lipoic acid helps reduce particle growth.

The infrared spectrum of electrospun PCL and PCL-Au fibers in the $4000-400 \mathrm{~cm}^{-1}$ region is shown in Figure 3. It is notable that the same spectrum was obtained for the PCL and PCL-AuNPs fibers. Regarding these spectra, it is easy to identify asymmetric and symmetric stretching bands for $\mathrm{CH}_{2}$ at 2949 and $2846 \mathrm{~cm}^{-1}$, respectively, and a stretching strong band for the carbonyl stretching mode around $1,727 \mathrm{~cm}^{-1}$ is observed and attributed to amorphous phases of the polymer. According to the literature, the band at $1294 \mathrm{~cm}^{-1}$ is assigned 


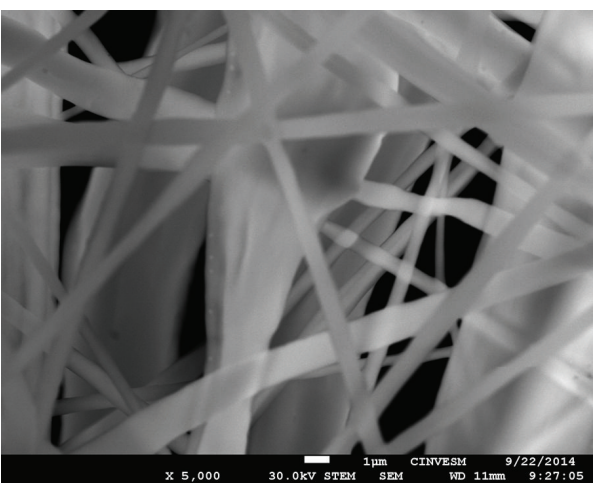

(a)

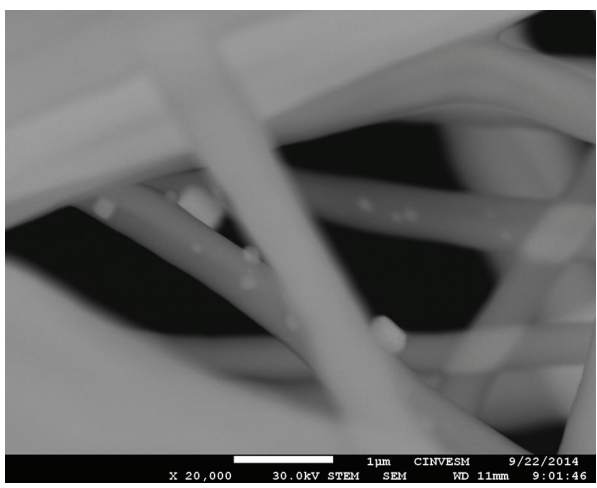

(c)

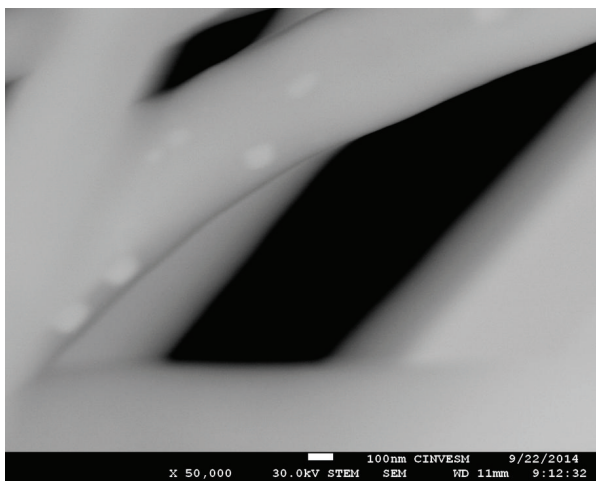

(e)

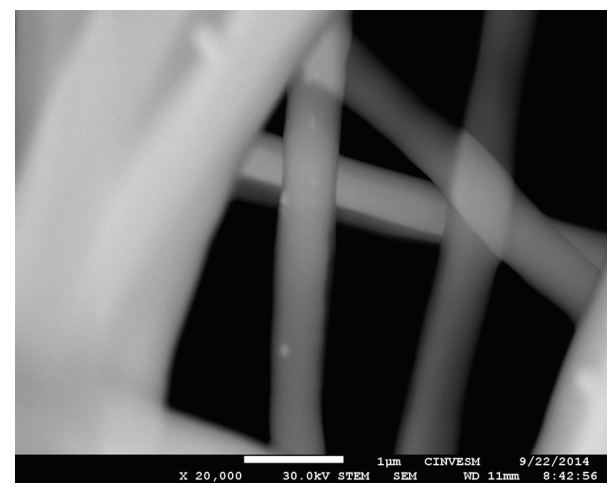

(b)

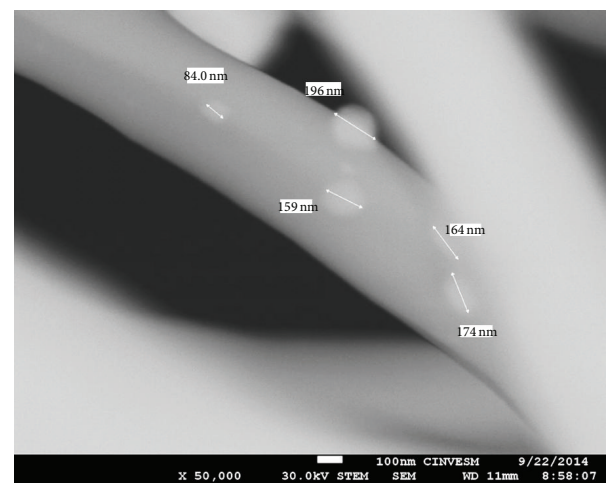

(d)

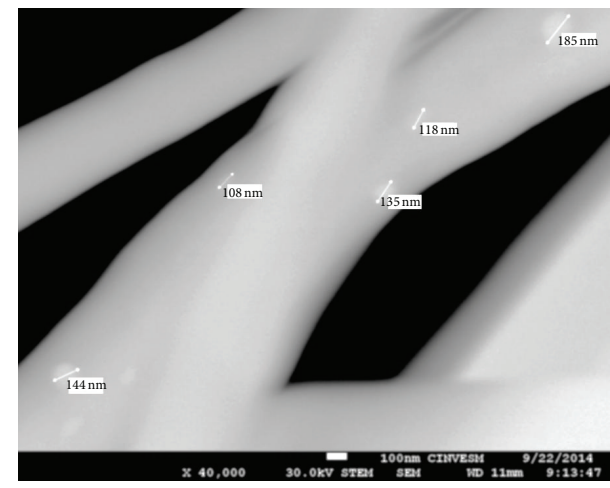

(f)

Figure 5: STEM micrographs of the PCL/AuNPs nanofibers composite: (a) electrospun PCL/AuNPs 5,000x; (b) electrospun PCL/AuNPs 20,000x (zone 1); (c) electrospun PCL-AuNPs 20,000x (zone 2); (d) electrospun PCL-AuNPs 50,000x (zone 2); (e) electrospun PCL-AuNPs 50,000x (zone 3); and (f) electrospun PCL-AuNPs 40,000x (zone 3).

to the backbone $\mathrm{C}-\mathrm{C}$ and $\mathrm{C}-\mathrm{O}$ stretching modes in the crystalline PCL. The strongest bands and their assignments are gathered in Table 1.

Figure 4 shows SEM images of the resulting PCL and PCL-AuNPs nanofibers. The average diameters of the PCL and PCL-AuNPs nanofibers were $1.42 \mu \mathrm{m} \pm 0.52$ and $1.21 \mu \mathrm{m}$ $\pm 0.45 \mu \mathrm{m}$, respectively. Figure 4 shows the effect of AuNPs additions. It is obvious that the charge density increases with the addition of Au nanoparticles to the solution. Thus, the ejected jets have stronger elongation forces in the electrical field. Therefore, this resulted in forming thinner composite fibers [17].
Figure 5 shows STEM micrographs of the PCL-AuNPs. The AuNPs can be observed on the surface of the fibers with round shape, which is mainly distributed from 30 to $180 \mathrm{~nm}$ into the fibers. At high magnification is noted easily in the incises (d) to (f) in Figure 5 the presence of some large particles, with diameter around 100 to $180 \mathrm{~nm}$ in white contrast, on the surface of electrospun nanofibers, which is likely due to the increased incidence of agglomerations of AuNPs, due to drying process used and poor dispersion of the particles in the PCL solution. Functionalization with lipoic acid helps to prevent growth and particle charge, which is necessary to prevent larger agglomerates shown in 


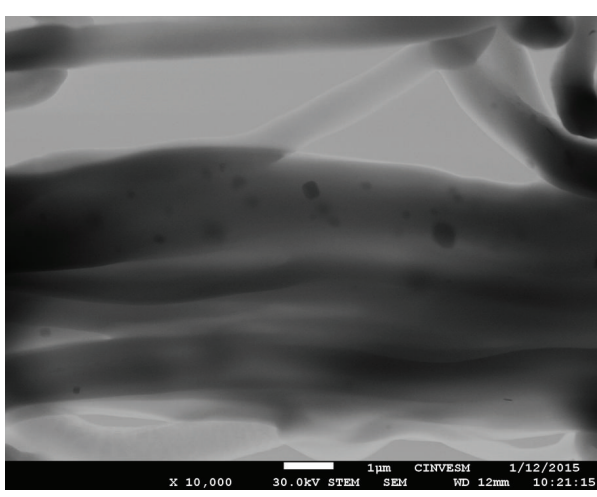

(a)

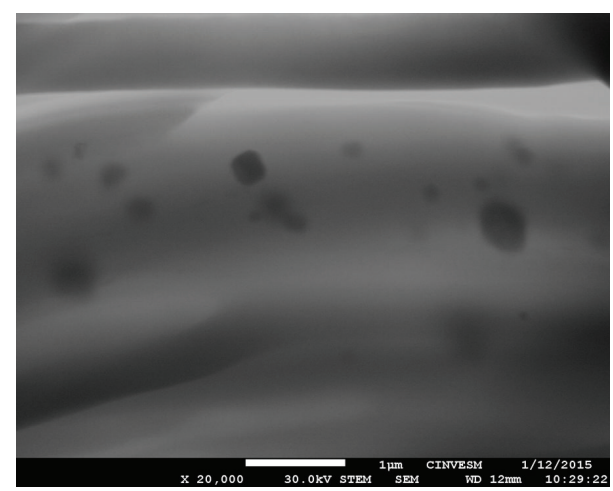

(b)

FIGURE 6: STEM micrographs of the PCL/AuNPs nanofibers composite without lipoic acid: (a) electrospun PCL/AuNPs 10,000x and (b) electrospun PCL/AuNPs 20,000x.

TABLE 1: Characteristic infrared bands of PCL.

\begin{tabular}{lcc}
\hline Position $\left(\mathrm{cm}^{-1}\right)$ & Vibrator & Abbreviation \\
\hline 2944 & Asymmetric $\mathrm{CH}_{2}$ stretching & $v_{\text {as }}\left(\mathrm{CH}_{2}\right)$ \\
2866 & Symmetric $\mathrm{CH}_{2}$ stretching & $v_{\mathrm{s}}\left(\mathrm{CH}_{2}\right)$ \\
2949 & Asymmetric $\mathrm{CH}_{2}$ stretching & $v_{\text {as }}\left(\mathrm{CH}_{2}\right)$ \\
2865 & Symmetric $\mathrm{CH}_{2}$ stretching & $v_{s}\left(\mathrm{CH}_{2}\right)$ \\
1724 & Carbonyl stretching & $v(\mathrm{C}=\mathrm{O})$ \\
1294 & C-O and C-C stretching in the & $v_{s}$ \\
1240 & crystalline phase & $v_{\text {as }}(\mathrm{COC})$ \\
1190 & Asymmetric COC stretching & $v_{(\mathrm{OC}-\mathrm{O})}$ \\
1168 & OC-O stretching & $v_{s}(\mathrm{COC})$ \\
1157 & Symmetric COC stretching & $v_{s}$ \\
\hline
\end{tabular}

Figure 6, and has a better dispersion of the particles within the precursor solution. The chemical composition of the PCL-AuNPs fibers was examined using energy dispersive Xray; the spectra indicated the presence of carbon and gold particles in the hybrid fibers.

\section{Conclusions}

PCL/AuNPs fibers were successfully fabricated by electrospinning of PCL-AuNPs acetone solution. The resulting PCL/AuNPs fibers have a smooth surface and uniform diameters. The AuNPs can be observed on the surface of the fibers with round shape, which mainly distributed from 30 to $180 \mathrm{~nm}$ in the nanofibers. The present approach to fabricating PCL/AuNPs nanofibers may be extended for producing other nanoparticle-containing composite nanofibrous materials.

\section{Conflict of Interests}

The authors declare that there is no conflict of interests regarding the publication of this paper.

\section{Acknowledgments}

Simón Yobanny Reyes-López gratefully acknowledges financial support by the CONACYT (Proyecto-204873) and PROMEP (F-PROMEP-39/Rev-03). Gerardo GonzálezGarcía gratefully acknowledges postdoctoral scholarship from Consejo Nacional de Ciencia y Tecnología (CONACYT) and technical support of Dora A. Huerta and Ana R. C for SEM and STEM analysis at Laboratorio Nacional de Nano y Biomateriales (LANNBIO), CINVESTAV-IPN Mérida by the projects CONACYT Lab-2009-01 no. 123913 and Fomix-Yucatan 2008-108160.

\section{References}

[1] Z. M. Huang, Y. Z. Zhang, M. Kotaki, and S. Ramakrishna, "A review on polymer nanofibers by electrospinning and their applications in nanocomposites," Composites Science and Technology, vol. 63, no. 15, pp. 2223-2253, 2003.

[2] D. Li and Y. Xia, "Electrospinning of nanofibers: reinventing the wheel?" Advanced Materials, vol. 16, no. 14, pp. 1151-1170, 2004.

[3] W. E. Teo and S. Ramakrishna, "A review on electrospinning design and nanofibre assemblies," Nanotechnology, vol. 17, no. 14, article R01, pp. R89-R106, 2006.

[4] D. Li, J. T. McCann, M. Gratt, and Y. Xia, "Photocatalytic deposition of gold nanoparticles on electrospun nanofibers of titania," Chemical Physics Letters, vol. 394, no. 4-6, pp. 387-391, 2004.

[5] T. K. Dash and V. B. Konkimalla, "Poly-e-caprolactone based formulations for drug delivery and tissue engineering: a review," Journal of Controlled Release, vol. 158, no. 1, pp. 15-33, 2012.

[6] F. E. Porbeni, I. D. Shin, X. Shuai et al., "Morphology and dynamics of the poly( $\epsilon$-caprolactone)-b-poly(L-lactide) diblock copolymer and its inclusion compound with $\alpha$-cyclodextrin: a solid-state 13C NMR study," Journal of Polymer Science Part B: Polymer Physics, vol. 43, no. 15, pp. 2086-2096, 2005.

[7] S. Y. Reyes-Lõpez and A. Martinez-Richa, "The ring-opening polymerization of epsilon-caprolactone catalyzed by molybdenum trioxide: a kinetic approach study using NMR and DSC data," Macromolecular Symposia, vol. 325-326, no. 1, pp. 21-37, 2013. 
[8] H. Liu, X. Ding, G. Zhou, P. Li, X. Wei, and Y. Fan, "Electrospinning of nanofibers for tissue engineering applications," Journal of Nanomaterials, vol. 2013, Article ID 495708, 11 pages, 2013.

[9] Y. Ikada and H. Tsuji, "Biodegradable polyesters for medical and ecological applications," Macromolecular Rapid Communications, vol. 21, no. 3, pp. 117-132, 2000.

[10] J. Wang, H.-B. Yao, D. He, C.-L. Zhang, and S.-H. Yu, "Facile fabrication of gold nanoparticles-poly(vinyl alcohol) electrospun water-stable nanofibrous mats: efficient substrate materials for biosensors," ACS Applied Materials and Interfaces, vol. 4, no. 4, pp. 1963-1971, 2012.

[11] C. A. E. Hamlett, S. N. Jayasinghe, and J. A. Preece, "Electrospinning nanosuspensions loaded with passivated Au nanoparticles," Tetrahedron, vol. 64, no. 36, pp. 8476-8483, 2008.

[12] S. Zhao, Z. Wang, X. Wei et al., "Comparison study of the effect of PVP and PANI nanofibers additives on membrane formation mechanism, structure and performance," Journal of Membrane Science, vol. 385-386, no. 1, pp. 110-122, 2011.

[13] Y.-N. Jiang, H.-Y. Mo, and D.-G. Yu, "Electrospun drug-loaded core-sheath PVP/zein nanofibers for biphasic drug release," International Journal of Pharmaceutics, vol. 438, no. 1-2, pp. 232239, 2012.

[14] W. Haiss, N. T. K. Thanh, J. Aveyard, and D. G. Fernig, "Determination of size and concentration of gold nanoparticles from UV-Vis spectra," Analytical Chemistry, vol. 79, no. 11, pp. 4215-4221, 2007.

[15] L. Wang, Y. Sun, J. Wang, and Z. Li, "Assembly of gold nanoparticles on electrospun polymer nanofiber film for SERS applications," Bulletin of the Korean Chemical Society, vol. 35, no. 1, pp. 30-34, 2014.

[16] M. C. Daniel and D. Astruc, "Gold nanoparticles: assembly, supramolecular chemistry, quantum-size-related properties, and applications toward biology, catalysis, and nanotechnology," Chemical Reviews, vol. 104, no. 1, pp. 293-346, 2004.

[17] W. K. Son, J. H. Youk, T. S. Lee, and W. H. Park, “The effects of solution properties and polyelectrolyte on electrospinning of ultrafine poly(ethylene oxide) fibers," Polymer, vol. 45, no. 9, pp. 2959-2966, 2004. 

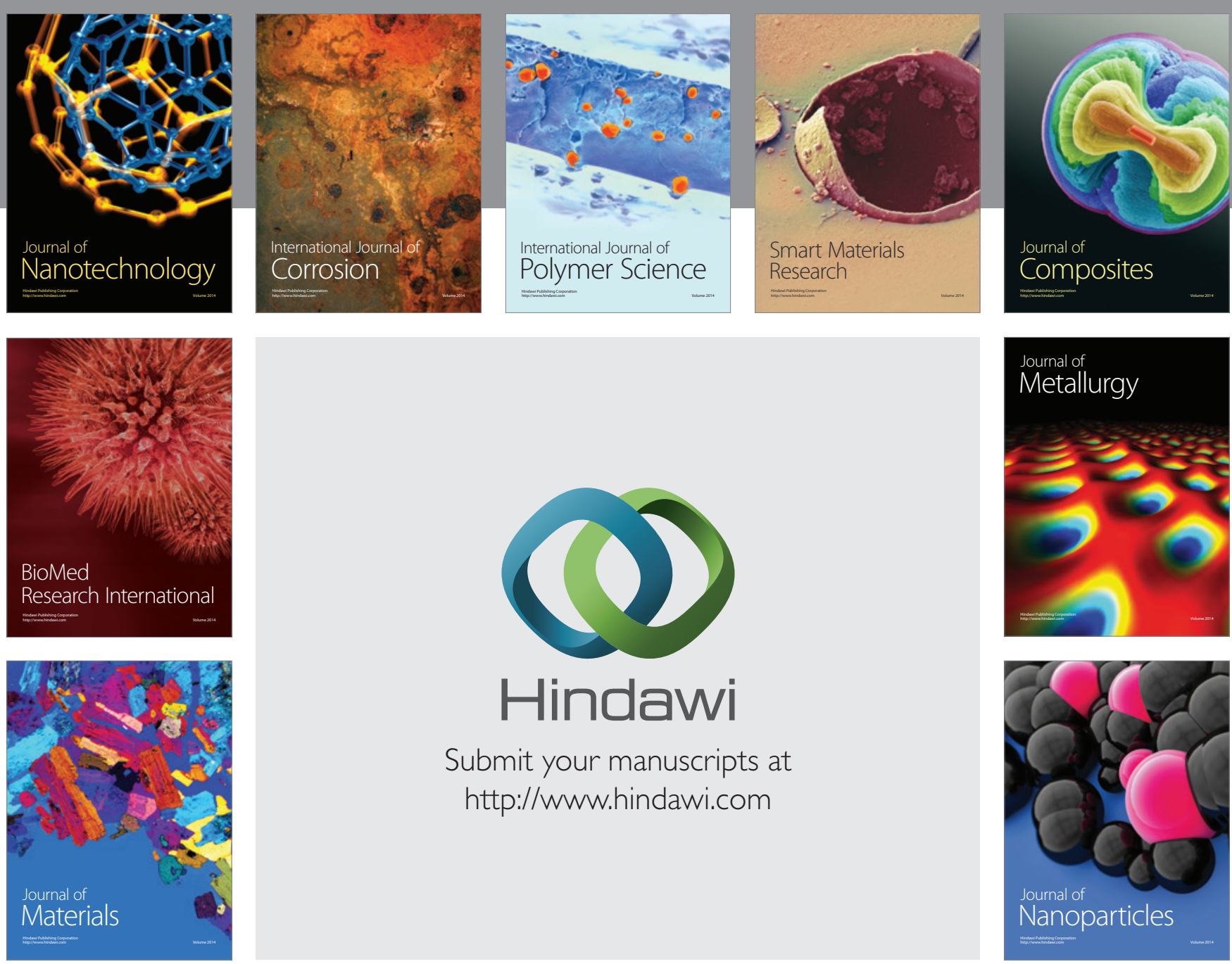

Submit your manuscripts at http://www.hindawi.com
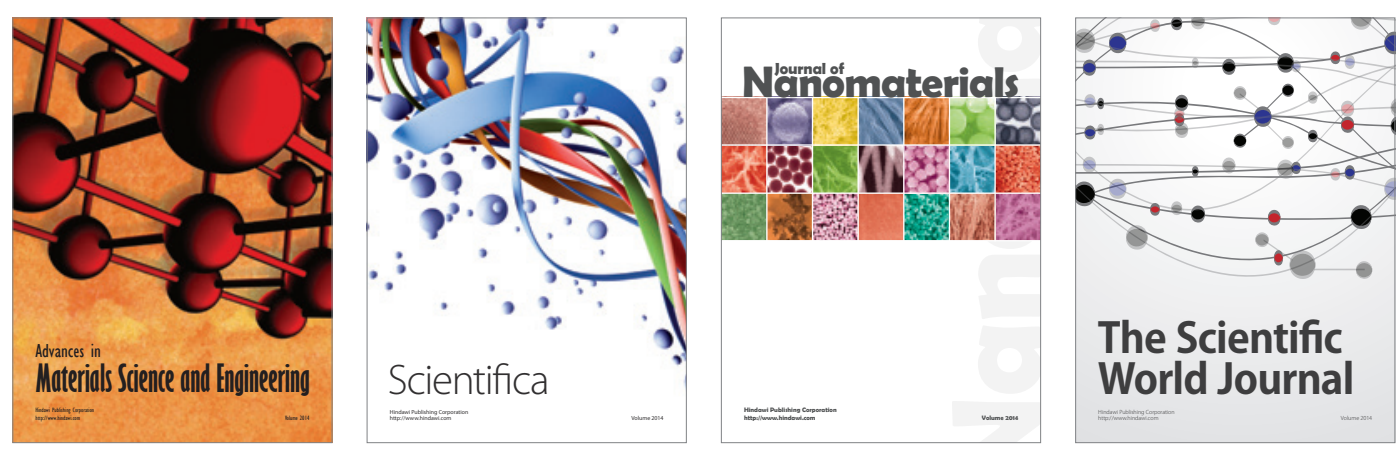

\section{The Scientific World Journal}
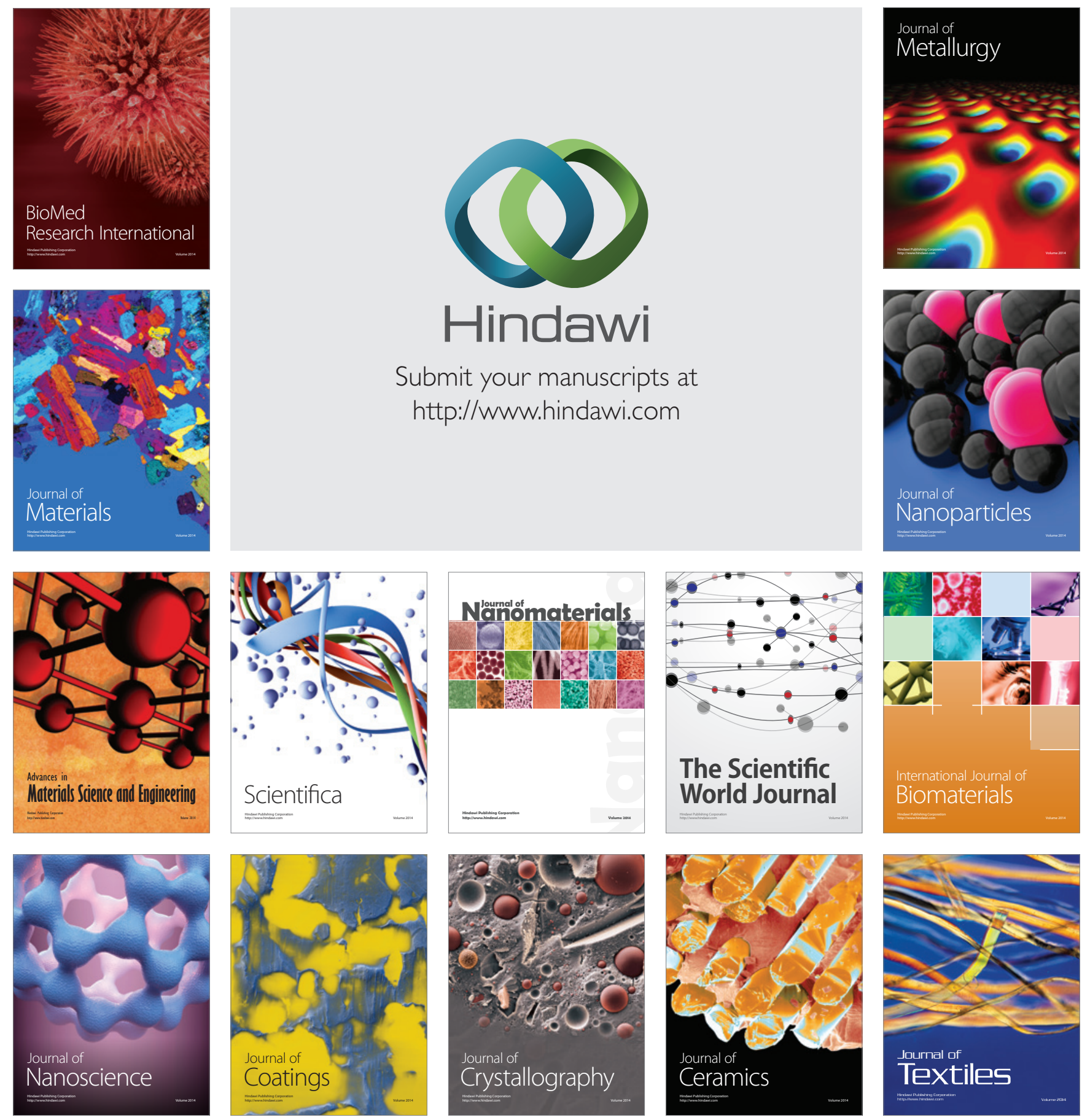